\title{
A performance-based funding da educação básica no Brasil
}

\author{
Performance-based funding of basic education in Brazil \\ El financiamiento basado en el desempeño de la educación básica en Brasil
}

Received: 01/29/2021 | Reviewed: 02/04/2021 | Accept: 02/17/2021 | Published: 02/24/2021

\begin{tabular}{|c|}
\hline 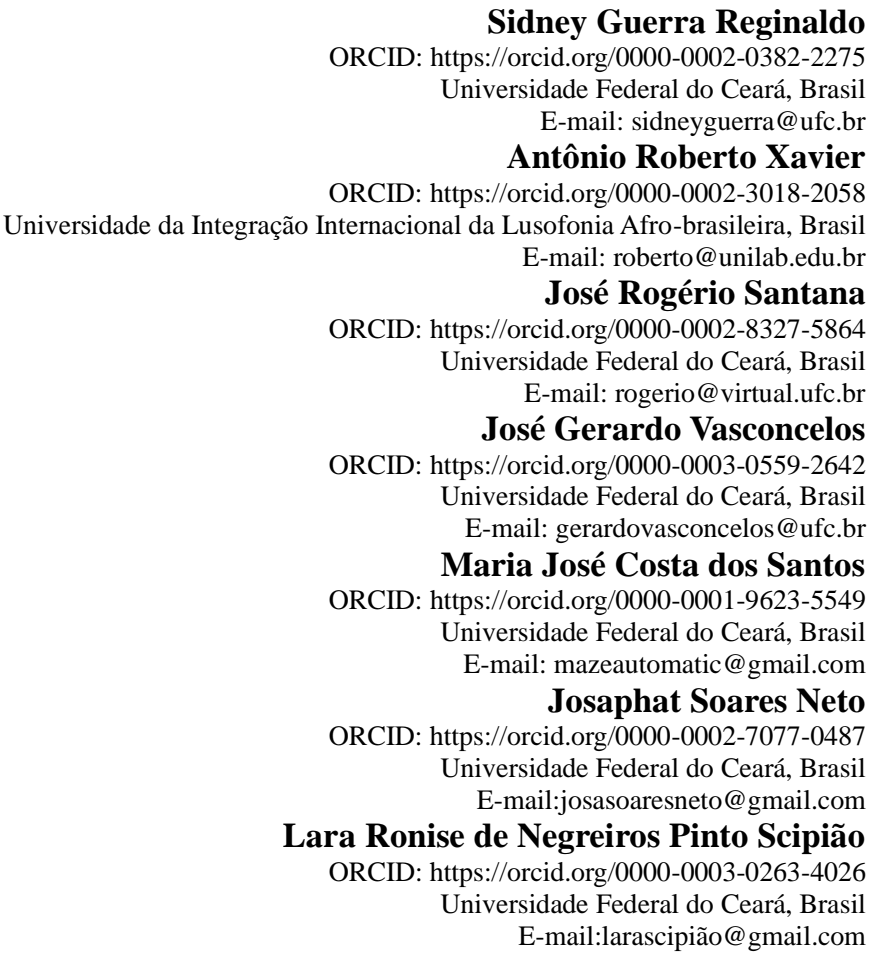 \\
\hline
\end{tabular}

\section{Resumo}

As diretrizes da Emenda Constitucional n. ${ }^{\circ}$ Emenda Constitucional n. ${ }^{\circ} 53$ que deu uma nova redação ao art. 60 do ato das disposições constitucionais transitórias (ADCT) criando o Fundo de Manutenção e Desenvolvimento da Educação Básica e de Valorização dos Profissionais da Educação FUNDEB, tendo como meta, no período de sua vigência de 10(dez) anos, melhorar a qualidade da educação básica brasileira, com o apoio de todos os entes federativos. Porém os resultados apresentados pelo Programa Internacional de Avaliação de Estudantes (PISA) revela que os investimentos na educação básica demonstra a falta de qualidade e a prática de se definir um projeto que traga resultados satisfatórios na performance-based funding dos nossos alunos. O presente artigo busca trazer uma reflexão sobre a perfomance dos alunos na educação básica, a partir dos resultados do PISA e os valores que foram investidos pelo (FUNDEB) na educação básica, permitindo, ao final, buscar novas possibilidades de melhoramento no desempenho dos alunos brasileiros nos diversos seguimentos educacionais. Para tanto, foram analisados descritivamente dados oficiais do governo no investimento na educação básica, utilizando de abordagens quantiqualitativa, aplicando o método hipotético-dedutivo, recorrendo a uma forma descritiva concentrado no objeto do investimento na educação básica pelo FUNDEB.

Palavras-chave: FUNDEB; PISA; Educação básica.

\begin{abstract}
The guidelines of Constitutional Amendment No. Constitutional Amendment No. 53 that gave a new writing to art. 60 of the act of transitional constitutional provisions (ADCT) creating the Fund for Maintenance and Development of Basic Education and Valorization of Education Professionals FUNDEB, with the goal, during its period of 10 (ten) years, to improve the quality of education Brazilian basic education, with the support of all federative entities. However, the results presented by the International Student Assessment Program (PISA) reveal that investments in basic education demonstrate the lack of quality and the practice of defining a project that brings satisfactory results in the performance-based funding of our students. This article seeks to bring a reflection on the performance of students in basic education, from the results of PISA and the values that were invested by (FUNDEB) in basic education, allowing, in the end, to seek new possibilities for improvement in student performance Brazilians in different
\end{abstract}


educational segments. To this end, official government data on investment in basic education were descriptively analyzed, using quantitative-qualitative approaches, applying the hypothetical-deductive method, using a descriptive form concentrated on the object of investment in basic education by FUNDEB.

Keywords: FUNDEB; PISA; Basic education.

\section{Resumen}

Los lineamientos de la Enmienda Constitucional No. La Enmienda Constitucional No. 53 que dio una nueva escribiendo al arte. 60 de la Ley de Disposiciones Constitucionales Transitorias (ADCT) que crea el Fondo de Mantenimiento y Desarrollo de la Educación Básica y Valorización de los Profesionales de la Educación FUNDEB, con el objetivo, durante su período de 10 (diez) años, de mejorar la calidad de la educación básica brasileña educación, con el apoyo de todas las entidades federativas. Sin embargo, los resultados presentados por el Programa Internacional de Evaluación de Estudiantes (PISA) revelan que las inversiones en educación básica demuestran la falta de calidad y la práctica de definir un proyecto que arroje resultados satisfactorios en la financiación basada en el desempeño de nuestros estudiantes. Este artículo busca traer una reflexión sobre el desempeño de los estudiantes en educación básica, a partir de los resultados de PISA y los valores que fueron investidos por (FUNDEB) en la educación básica, permitiendo, al final, buscar nuevas posibilidades de mejora en desempeño estudiantil brasileños en diferentes segmentos educativos. Para ello, se analizaron descriptivamente los datos oficiales del gobierno sobre inversión en educación básica, utilizando enfoques cuantitativo-cualitativos, aplicando el método hipotéticodeductivo, utilizando una forma descriptiva concentrada en el objeto de inversión en educación básica por FUNDEB. Palabras clave: FUNDEB; PISA; Educación básica.

\section{Introdução}

De acordo com o resultado divulgado pelo Programa Internacional de Avaliação de Estudantes (Pisa), em dezembro de 2019, aplicado em 79 países e regiões a 600 mil estudantes de 15 anos, onde no Brasil cerca de 10,7 mil estudantes de 638 escolas fizeram as provas, em uma escala de 6, o país obteve no nível $2 \mathrm{em}$ leitura, no nível 1 em matemática e também no nível 1 em ciências. 6. Pelos critérios da Organização para a Cooperação e Desenvolvimento Econômico (OCDE), o nível 2 é considerado o mínimo adequado.

Os resultados do PISA, que são os mais utilizados, junto a opinião pública, só constata os fracos níveis de aproveitamento e desempenho escolar no Brasil, ficaram abaixo das médias dos países membro e parceiros da OCDE, não potencializando o investimento que vem sendo efetuado pelo Fundo de Manutenção e Desenvolvimento da Educação Básica e de Valorização dos Profissionais da Educação (FUNDEB).

O que de fato ocorre com o fraco desempenho dos alunos brasileiros nas avaliações do PISA se existe investimento direcionados a esse segmento, no caso, da educação básica, como é o FUNDEB?

Analisar o que evencia o fraco desempenho dos alunos brasileiros da educação básica no PISA, que tem por base os resultados (Performance-based funding) avaliativos, é uma forma de dar uma maior eficiência ao investimento público, na área da educação, considerado os critérios da eficiência e da eficácia.

Para tanto, se faz necessário analisar de forma descritiva os dados apresentados pelo governo quanto ao investimento do FUNDEB na educação básica e os resultados apresentados pelo PISA referente ao desempenho dos alunos brasileiros, onde se constatou o baixo rendimento do Brasil ao longo dos anos, em comparação a outros países. Procurar saber, diante dos resultados apresentados pelo PISA, as implicações com o investimento do FUNDEB na educação básica, e se as condições sociais e econômicas do país exercem alguma influência sobre o baixo rendimento dos alunos brasileiros ou se de fato o quantum investido não condiz com a qualidade ao investimento do FUNDEB à educação básica?

A essas indagações, com abordagens quanti-qualitativa, utilizando o método hipotético-dedutivo, recorrendo a uma forma descritiva configurada no objeto do investimento na educação básica pelo FUNDEB, o desempenho dos alunos brasileiros e a qualidade do desenvolvimento no capital humano, precedido de uma análise dos fenômenos da atividade econômica e política voltada para a educação, estabelecendo o período temporal da Emenda Constitucional n. ${ }^{\circ} 53$ que deu uma 
nova redação ao art. 60 do ato das disposições constitucionais transitórias (ADCT) criando o FUNDEB, para ao final fazer as considerações pertinentes à temática proposta.

Em relação a atividade econômica e a política educacional desenvolvida pelo FUNDEB, que por um status de orientação se torna uma atividade de fomento extra-econômica, porque forma uma atividade para obtenção as utilidades necessárias para fins sociais, e no sentido lato sensu de incluir a obtenção de bens em espécie ao Estado, de forma organizada, assume um protagonismo nos problemas sociais e políticos emergindo um consenso de que, como asseverava Marx "é o modo de produção da vida material que condiciona o desenvolvimento da vida social, política e intelectual em geral" (Marx, 2008).

Nesse sentido, orientar-se em atividades extra-econômicas de natureza intelectual cientifica e tecnológica, obstruindo natureza ideológica seja de cunho ético, religioso e partidário, que valoriza à prática docente, desempenha um papel importante não só para a sociedade a qual se exercita mas para todos os atores sociais, com o reconhecimento da importância que esta assume na evolução no campo do ensino, na produção de grau de desenvolvimento social e individual dos indivíduos.

O abastecimento dessa valorização na educação básica e dos profissionais na área educação, economicamente administrada pelos governos, por meio de financiamento público, derivado de arrecadações próprias destinadas ao uso específico, devem ser respeitado ao viés dos princípios e preceitos constitucionais, já que a economia assume o seu papel de protagonismo na anatomia da sociedade civil.

Nesse contexto, os problemas sociais, políticos e econômicos, enfrentados nos últimos anos no Brasil, tem causado efeitos direto nas atividades de desenvolvimento de escolar e na qualificação dos docentes na educação pública, que hoje sofre com a possibilidade de um desinvestimento nesse setor, por força do decréscimo da atividade econômica do país. Todavia, há de se considerar que, o abastecimento com determinadas atividades de utilidades economicamente administradas, por vezes, não tem a real importância, no plano do capitalismo politicamente aquisitivo orientado pelo mercado com a estereotipagem do retorno imediato do capital empregado, como é o caso da política educacional.

É verdade que em uma análise direta, não se pode ignorar que os governos têm se preocupado com a realidade educacional brasileira, até mesmo por força de preceito constitucional, no que diz respeito aos seus aspectos de financiamento de verbas públicas. Porém, não se pode ignorar, confrontando com uma significativa dificuldade de obtenção de resultados práticos das estatísticas disponíveis, que houve uma queda significativa, ao longo dos anos, no direcionamento do financiamento público para a educação. É certo que não se pode desassociar a política educacional da política econômica, muito embora a categoria de "superávit" pertença a economia monetária pública, o comportamento desta orienta o fluxo econômico do investimento/financiamento da política educacional.

Como fomento ao investimento na área de manutenção e desenvolvimento da educação básica e de valorização dos profissionais da educação, o governo federal editou no ano de 2006 a Emenda Constitucional n. 53 que deu uma nova redação ao art. 60 do ato das disposições constitucionais transitórias (ADCT) ${ }^{1}$, criando um fundo econômico, composto de Estados, Municípios e o Distrito Federal, para redistribuição de recursos públicos a fim de valorizar os profissionais da educação e desenvolver e manter funcionando todas as etapas da Educação Básica - desde creches, Pré-escola, Educação Infantil, Ensino Fundamental, Ensino Médio até a Educação de Jovens e Adultos (EJA), denominado de Fundo de Manutenção e Desenvolvimento da Educação Básica e de Valorização dos Profissionais da Educação (Fundeb), passando a vigorar por 14 (quatorze) anos com término previsto para 2020.

\footnotetext{
${ }^{1}$ Art. $2^{\circ} \mathrm{O}$ art. 60 do Ato das Disposições Constitucionais Transitórias passa a vigorar com a seguinte redação: (Vigência)

“Art. 60. Até o $14^{\circ}$ (décimo quarto) ano a partir da promulgação desta Emenda Constitucional, os Estados, o Distrito Federal e os Municípios destinarão parte dos recursos a que se refere o caput do art. 212 da Constituição Federal à manutenção e desenvolvimento da educação básica e à remuneração condigna dos trabalhadores da educação, respeitadas as seguintes disposições:
} 
A política de criação desse fundo, tem como objetivo diminuir as desigualdades de recursos entre as redes de ensino fomentando o investimento por aluno, visando dar uma maior segurança financeira aos Estados e Municípios na expansão de responsabilidade com a educação, seguindo as regras do limite de gastos previsto no art. 70 da Lei n. ${ }^{\circ} 9.394$, de 20 de dezembro de 1996 - Lei de diretrizes e bases da educação nacional (LDB)².

A partir do conceito de construção de um fundo de investimento público, como política educacional ou mesmo como stand de política pública, será analisado o processo de criação do Fundo de Manutenção e Desenvolvimento da Educação Básica e de Valorização dos Profissionais da Educação (Fundeb) e seus resultados na construção de uma política educacional mais eficaz da educação básica nas suas relações com as mudanças sociais, assumindo o conhecimento como prática social, estabelecendo um quadro comparativo desde o início de sua vigência, marcado, de um lado, pelas consequências de muitas crianças ainda se encontrarem fora das atividades escolares ou mesmo estarem em processo de abandono escolar, causado por diversos fatores sociais, até a atual situação, e, estando próximo ao seu término, do outro, pelo desempenho nos debates sobre a eficácia da aplicação desse fundo e sua continuidade no financiamento público para a manutenção da educação básica e valorização do profissionais da educação.

Será necessário comparar os dados apresentados pelo FUNDEB com os outros modelos de financiamento público destinados à educação, como instrumentos de desenvolvimentos e a sua dependência do financiamento estatal, seja em períodos de maior ou menor crescimento econômico. Para tornar compreensível, será necessário desenvolver um quadro teórico sobre a educação brasileira, para depois contextualizar a realidade em que se encontra, desde a vigência do FUNDEB até o ano de 2019, avançando em hipóteses explicativas para a continuidade ou não desse fundo de investimento na política educacional brasileira.

O desafio de novas políticas na educação, centrada na prioridade de se ter um maior número possível de crianças na escola, evitando a evasão e qualificando os profissionais da educação, se tornou um fonte renovadora, mas que os resultados mostram um crescimento muito lento diante das diretrizes esperadas. Nesta perspectiva, é de se revelar o importante papel que a educação básica e a qualificação dos profissionais da educação tem na formação do aluno, entendida como um ponto de partida, centralizada não tão somente na aquisição do conhecimento mas na afirmação de uma formação de inclusão social, igualdade de oportunidades e uma cultura de respeito mútuo e valores fundamentais, melhorando o acesso a uma aprendizagem de qualidade para todos.

O futuro não se pode alçar em um passado, já que o presente demonstra a necessidade de uma constante mudança para se alcançar os objetivos desejados, daí sempre a busca de uma melhor qualidade para a educação escolar, em todos os níveis, e em especial ao ensino básico como um pilar de desenvolvimento social, enquanto espaço público democrático.

Em relação ao financiamento público da educação básica no Brasil, pode-se ressaltar que a qualidade da educação da escola pública sempre foi alvo de polêmicas no Brasil, dentre elas a influência sofrida pelas formas de financiamento público, ou seja, as fontes, destinos e forma de gestão dos recursos aplicados à educação. Estudos como o de Martins (2010), Pinto (2018), Araújo e Oliveira (2019), Silva (2019), Menezes Filho (2019) e Politi (2019) são exemplos que

\footnotetext{
2 Art. 70. Considerar-se-ão como de manutenção e desenvolvimento do ensino as despesas realizadas com vistas à consecução dos objetivos básicos das instituições educacionais de todos os níveis, compreendendo as que se destinam a:

I - remuneração e aperfeiçoamento do pessoal docente e demais profissionais da educação;

II - aquisição, manutenção, construção e conservação de instalações e equipamentos necessários ao ensino;

III - uso e manutenção de bens e serviços vinculados ao ensino;

IV - levantamentos estatísticos, estudos e pesquisas visando precipuamente ao aprimoramento da qualidade e à expansão do ensino;

V - realização de atividades-meio necessárias ao funcionamento dos sistemas de ensino;

VI - concessão de bolsas de estudo a alunos de escolas públicas e privadas;

VII - amortização e custeio de operações de crédito destinadas a atender ao disposto nos incisos deste artigo;

VIII - aquisição de material didático-escolar e manutenção de programas de transporte escolar.
} 
demonstram que se trata de um tema que vem sendo exaustivamente analisado, aumentando o interesse no assunto com o término do prazo de vigência da legislação do FUNDEB ao final de 2020.

A educação é concebida como um conjunto de recursos que visam estabelecer e apoderar-se de estratégias aplicáveis de metodologias, conteúdos e recursos humanos, proporcionando nas mais diversas instâncias do universo escolar, formação cidadã, sobretudo fomentando a valorização humana de forma integralista principalmente no que diz respeito à diversidade e à apropriação de conhecimentos gerais. O financiamento público é a principal forma de distribuição de recursos para que esse conjunto de fato possa funcionar, sendo ele oriundo de arrecadação tributária.

No que concerne às despesas com educação, a Lei de Responsabilidade Fiscal (LRF), em seu artigo IV, "b", dispõe que os limites da educação deverão ser obedecidos de acordo com o que foi estabelecido em Constituição Federal, em seu art. 212, que: "A União aplicará, anualmente, nunca menos de dezoito, e os Estados, o Distrito Federal e os Municípios vinte e cinco por cento, no mínimo, da receita resultante de impostos, compreendida a proveniente de transferências, na manutenção e desenvolvimento do ensino".

Assim, tem-se com base na Constituição Federal e confirmado pela LRF, os limites mínimos de gasto com a Educação, estabelecendo $18 \%$ a ser destinado pela União e $25 \%$ a ser destinado pelos Estados e Municípios. Vale ressaltar que dos 25\% destinados pelos Estados e Municípios, 60\% devem ser direcionados ao Ensino Fundamental e os $40 \%$ restantes ao financiamento de outros níveis de ensino, como Ensino Infantil e Ensino Médio.

Vale destacar o Fundo de Manutenção e Desenvolvimento da Educação Básica e de Valorização dos Profissionais da Educação (FUNDEB), onde 60\% desses recursos devem ser destinado aos profissionais de magistério da educação básica. Quanto ao mínimo a ser gasto dos recursos do FUNDEB tem-se 95\%, os demais 5\% podem ser utilizados no trimestre seguinte e com a abertura de crédito nacional. Os recursos do FUNDEB estarão de acordo com o número de matrículas efetivadas na rede estadual e municipal.

Apesar de uma política de financiamento bem delimitada, Pinto (2018) elucida que o FUNDEB não tem conseguido atingir suas finalidades, com um valor baixo por aluno, refletindo de forma clara na questão história brasileira de desigualdade educacional. Dados do Instituto Nacional de Estudos e Pesquisas Educacionais Anísio Teixeira (INEP) demonstram que em 2018 somente 5\% do Produto Interno Bruto (PIB) brasileiro foi destinado à educação, o que indica o quão baixo é o volume de recursos aplicados à educação.

A dimensão operacional nos seus aspectos de assistência técnica e financeira está fundamentada no Plano de Metas Compromisso Todos pela Educação por meio de decreto $n^{\circ}$ 6.094/2007 que atende prescrições da LDBEN no 9.394/1996 e mandato da Constituição Federal de 1988 (art.211, inciso 1º):

A União, os Estados, o distrito Federal e os Municípios organizarão em regime de colaboração seus sistemas de ensino. Inciso $1^{\circ}$ a União organizará e financiará o sistema Federal de ensino e dos Territórios, e prestará assistência técnica e financeira aos Estados, ao Distrito Federal e aos municípios para o desenvolvimento de seus sistemas de ensino e o atendimento prioritário à escolaridade obrigatória.

O Programa de Desenvolvimento Educacional (PDE) gerou plano de ações financiáveis através de programas como o PDE Escola (2007) e o PDE Interativo que surgiu em 2012. Através deles o governo gera verbas de custeio para as escolas (procedimento via online) com metas viáveis (que subsidiarão a liberação de recursos) para a melhoria de aprendizagem dos alunos, facilitação do trabalho docente, entre outros, e, consequentemente, o alcance das metas previstas no IDEB.

Para que se possa compreender a dimensão dos problemas relacionados ao financiamento público da educação básica, toma-se como base a última auditoria realizada pelos Tribunais de Contas brasileiros ocorrida no ano de 2013 
coordenada para identificar os principais problemas que afetam a qualidade e a cobertura do ensino no Brasil, bem como avaliar a ações governamentais destinadas a eliminar ou mitigar suas causas.

O Ensino Fundamental foi escolhido por ser um nível da educação básica que apresenta grandes desafios em termos de melhoria do ensino e de indicadores educacionais. De acordo com a Lei de Diretrizes e Fundamentos da Educação Brasileira (LDB), cabe aos Estados atuar principalmente em escolas educação. As redes estaduais concentram cerca de $97 \%$ das matrículas desse nível educacional.

A auditoria coordenada foi realizada por mais de 90 auditores da equipe do Tribunal Federal das Contas do Brasil e de outros 28 tribunais de contas brasileiros. Aproximadamente 580 escolas em todo o Brasil foram visitadas. Dentre os principais achados cita-se: as informações do Sistema de Informação sobre Orçamentos Públicos na Educação (SIOPE) divergem a partir de informações de outras fontes de dados de execução orçamentária, podendo, portanto, não refletir os gastos com educação; há evidências de que o ensino médio ainda está subfinanciado no Brasil; não há definição de padrões mínimos de qualidade educacional, fato que dificulta estimar o valor mínimo por aluno que garanta uma educação de qualidade e sirva como um parâmetro orientador dos recursos adicionais que o Governo Federal deve fornecer ao FUNDEB de cada Estado.

O relatório gerado pelos Tribunais de Contas informou que a sistemática de transferências voluntárias conduzidas pelo Ministério da Educação (MEC) para os Estados e para o Distrito Federal não assegura que a assistência financeira do Governo Federal através desta modalidade realmente beneficia as redes que mais precisam de suporte. Com isso é sugerido definir, a partir desses padrões, o valor mínimo por aluno que garanta a educação de qualidade e serve como um parâmetro orientador para os fundos adicionais que o Federal Governo deve transferir para o FUNDEB de cada Estado (art. $60^{\circ}$, inciso V, do ADCT - Tratado Lei de Disposições Constitucionais).

O estudo realizado por Politi (2019) demonstrou que o FUNDEB inegavelmente contribuiu para a redução da desigualdade entre os municípios, todavia, as diferenças de financiamento ainda permanecem muito grandes. Para modificar essa realidade, de acordo com o autor, seria necessário ou mudar a forma de redistribuição dos recursos ou aumentar o montante dos recursos investidos.

Resultado semelhante foi verificado na pesquisa de Menezes (2019), todavia, ressalta que o FUNDEB não tem como função melhorar a eficiência dos gastos com educação, nem mesmo possui instrumentos para tanto, considerando que existem municípios que com o mesmo nível de gasto possuem mais ou menos eficiência, verificando que seus resultados não são afetados pelas regras do referido fundo. Sendo esse resultado ratificado por Silva (2019), que afirma que a o FUNDEB não pode ser responsabilizado pelas melhorias ou fracassos nos resultados.

O que se verifica é uma necessidade discussões que visem outras dimensões das políticas de financiamento público da Educação básica, visto que não é possível deslumbrar aumento dos recursos, com a mudança de sua gestão mostrando-se como uma possibilidade mais clara de melhoria de sua eficácia.

\section{Metodologia}

O presente artigo trata-se de um estudo com abordagem quanti-qualitativa, utilizando o método hipotético-dedutivo, recorrendo a uma forma descritiva configurada no objeto de estudo que relaciona o investimento na educação básica pelo FUNDEB; o desempenho dos alunos brasileiros e a qualidade do desenvolvimento no capital humano. Posteriormente, foi feita uma análise dos fenômenos da atividade econômica e política voltada para a educação, estabelecendo o período temporal da Emenda Constitucional n. ${ }^{\circ} 53$ que deu uma nova redação ao art. 60 do ato das disposições constitucionais transitórias (ADCT) criando o FUNDEB, para ao final fazer as considerações pertinentes à temática proposta. 


\section{Resultados e Discussão}

Em relação a performance do investimento na educação baseada em resultados e desempenhos, pode-se iniciar a discussão de que todo projeto político nasce de uma conjuntura social debilitada, com apresentações de soluções que possam viabilizar o melhoramento dos problemas sociais e econômicos que afligem os indivíduos. As reformas apresentadas gozam sempre de forte apoio que pretende gerar transformações significativas na sociedade. No caso da educação é bem social muito marcado pelo cidadão comum, como sendo um objetivo de aspirações e aperfeiçoamento da sociedade, eliminando os efeitos debilitantes da desigualdade.

De um ponto de vista histórico, dentro desse contexto, o discurso político sobre a educação, fundamentado e cheio de boas intenções, torna-se um grande recurso para uma convergência de aspirações eletivas, com apresentações de vários projetos de políticas públicas, já que a educação é uma matéria de senso comum para a retórica do discurso, destinado sempre a fazer uma plataforma mais eficiente, capaz de superar as suas próprias limitações.

Porém, todo projeto de política educacional, visando reformas de melhorias nesse setor, mostra o envolvimento de verbas públicas como fonte privilegiada de financiamento. Os investimentos em políticas educacionais, são condições de ajustes para o progresso social e econômico de um país, como elemento importante de adequação, eficiência e eficácia. Essa conjuntura, sempre à dependência de reformas políticas e econômicas, enfrenta inconsistências pela demora na obtenção de seus resultados, frente aos investimentos recebidos, nas práticas de planejamento, implementação, monitoramento e avaliação.

Não se pode ignorar que, muitas vezes as mudanças de governos e as várias crises na política e na economia no Brasil, afeta todo o sistema da política educacional, até mesmo por falta de um modelo contínuo sustentável. Os indicadores, por mais técnicos que sejam, se encontram relacionados e dependentes de decisões políticas que se pretendem alcançar. Ao mesmo tempo que contribuem para dar uma maior transparência da gestão no setor educacional, os indicadores de resultados podem apontar ou gerar distorções na metodologia empregada, tornando, por vezes, ineficiente o resultado obtido valorizando a quantidade em detrimento da qualidade.

Os fundos de verbas públicas, neste caso, emergem como alternativa para fomentar o financiamento em determinada área social, no preciso momento em que se verifica algum declínio, com capacidade de introduzir mudanças significativas que possa assegurar o seu desenvolvimento e crescimento, diante de indicadores de resultados que demonstrem a urgência do investimento naquele setor. Desta forma, surge o FUNDEB, por meio da Emenda Constitucional n. ${ }^{\circ 53}$, para pôr em execução uma estratégia de mudança visando manter e desenvolver a educação básica e valorizando os profissionais da educação.

A circularidade dos fatos apresentados, gerando a criação do FUNDEB, passando pela teoria e desaguando na prática, é um processo de convergência para a formação de um projeto de desenvolvimento, de política racional de intervenção do Estado, como elemento fundamental para o controle contínuo de reformas no melhorando de sua atividade social da educação.

Nesse contexto, a educação é muita marcada no contexto social do cidadão, com objetivo de aperfeiçoamento da sociedade. Todas as suas aspirações convergem democraticamente para a eliminar efeitos de desigualdades sociais, dando um novo impulso de expectativa para o enriquecimento material do indivíduo. A partir desse senso se monitora continuamente os resultados dessa expectativa, na coleta dos dados representativos, de forma progressiva e eficiente, para superar as suas limitações e contradições. Daí a necessidade de contínuo investimento nessa área específica, por parte dos entes federados.

Esse período de construção, em que o Estado dispõe de meios financeiros adequados aos propósitos educacionais, com a criação do FUNDEB por meio da Emenda Constitucional de n. ${ }^{\circ} 53$, conduziram a uma mudança no sistema de controle 
tradicional do Estado, passando a dar uma maior relevância aos resultados do que mesmo aos processos burocráticos, gerindo os recurso de forma mais eficiente.

Curristine (2005, p. 138) atesta que a necessidade atual de servir os interesses coletivos com critérios de justiça e equidade e uma pressão mais forte no sentido da eficiência conduziram à mudança de paradigma de um sistema tradicional burocrático para um sistema flexível, inovador e preocupado com a apresentação de resultados.

Em dados históricos, o FUNDEB foi implementado quando o Brasil atingia um nível de equilíbrio em seu Produto Interno Bruto (PIB). Isso foi um dos fatores que geraram condições econômicas favoráveis, à época, para a criação e construção de novo sistema de investimento na área da educação, decorrente de um outro sistema de fundos de investimentos públicos o FUNDEF - Fundo de Manutenção e Desenvolvimento do Ensino Fundamental e de Valorização do Magistério -, criado pela Emenda Constitucional n. ${ }^{\circ}$ 14/96, regulamentado pela Lei n. ${ }^{\circ}$ 9.424/96 e pelo Decreto n. ${ }^{\circ}$ 2.264/97 e implantado automaticamente em janeiro de 1998 em todo o País, garantindo uma subvinculação dos recursos da educação para o Ensino Fundamental, para cada Estado e município que recebia o equivalente ao número de alunos matriculados na sua rede pública do Ensino Fundamental.

Em traços gerais, o Brasil se desvincula de um fundo (FUNDEF) se vinculando a um outro fundo (FUNDEB) para dar continuidade aos mesmos propósitos, com diferente perfomance, coleta de resultados e estrutura na distribuição dos recursos. Os períodos desses financiamentos são cíclicos, com prazo determinado de sua aplicação (quantificação) e resultados (qualificação) adequados aos seus propósitos educacionais. O fundo de financiamento continua a ser uma fonte privilegiada para a área da educação, representando um sustento significativo à qualidade do ensino no Brasil, apesar de um decréscimo na execução das despesas, a partir de 2017, conforme se observa no gráfico da (Figura 1).

Figura 1: Evolução histórica da execução das despesas na área de atuação da educação.

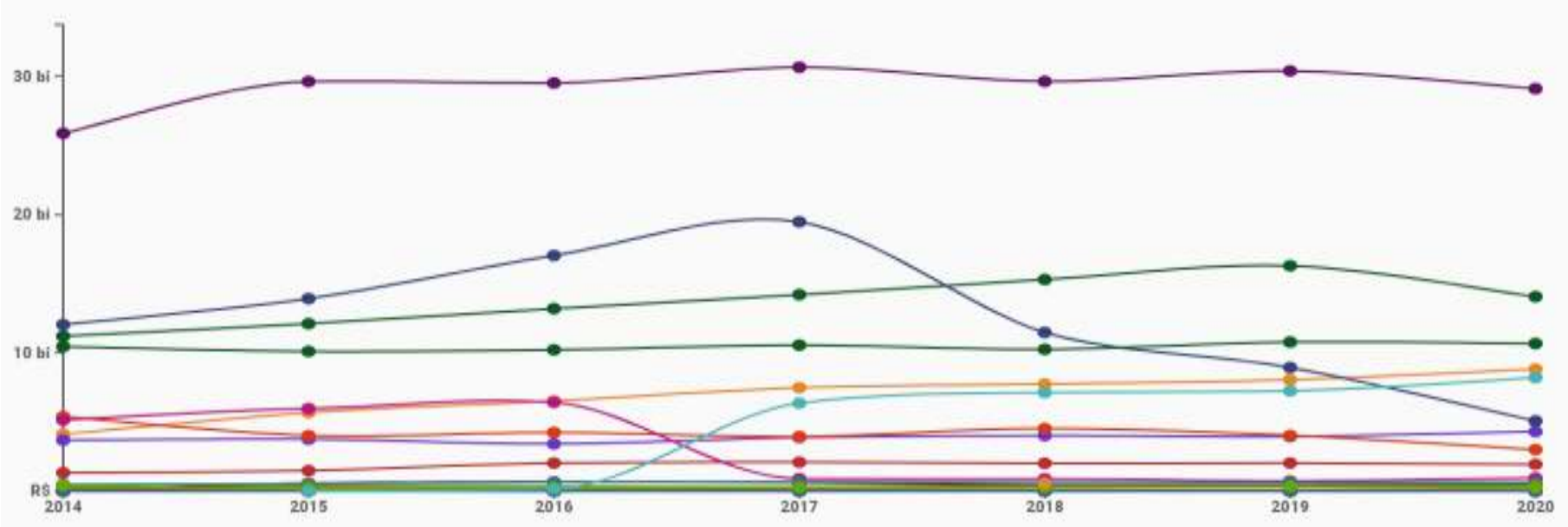




\section{Legenda:}

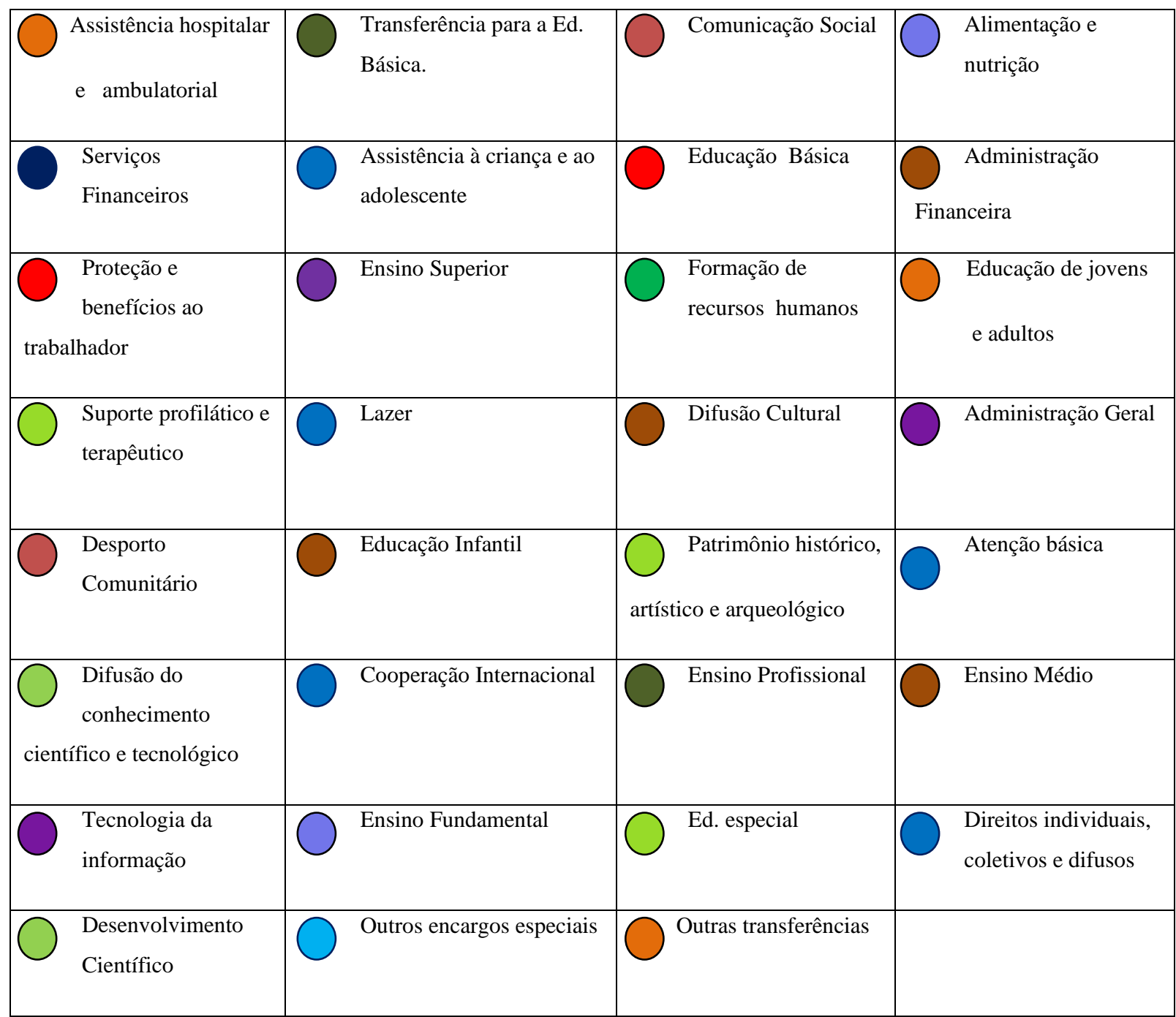

Fonte: http://www.portaltransparencia.gov.br/funcoes/12-educacao?ano=2019 (2019).

Podemos destacar a partir do gráfico acima que houve um decréscimo nos serviços financeiros, principalmente na transferência de recursos para Educação Básica e na proteção e benefícios ao trabalhador.

Mau grado estas dificuldades reais, com a queda significativa das despesas de educação, o modelo apresentado pelo FUNDEB, no que diz respeito ao financiamento, fornece indicadores acerca das opções perseguidas no âmbito da política de educação, como o órgão que mais aplica recursos na área de educação no ano de (2019), como mostra o gráfico da (Figura 2). 
Figura 2: Representação dos dez órgãos que aplicam mais recursos ( $\mathrm{R} \$$ bilhoes).

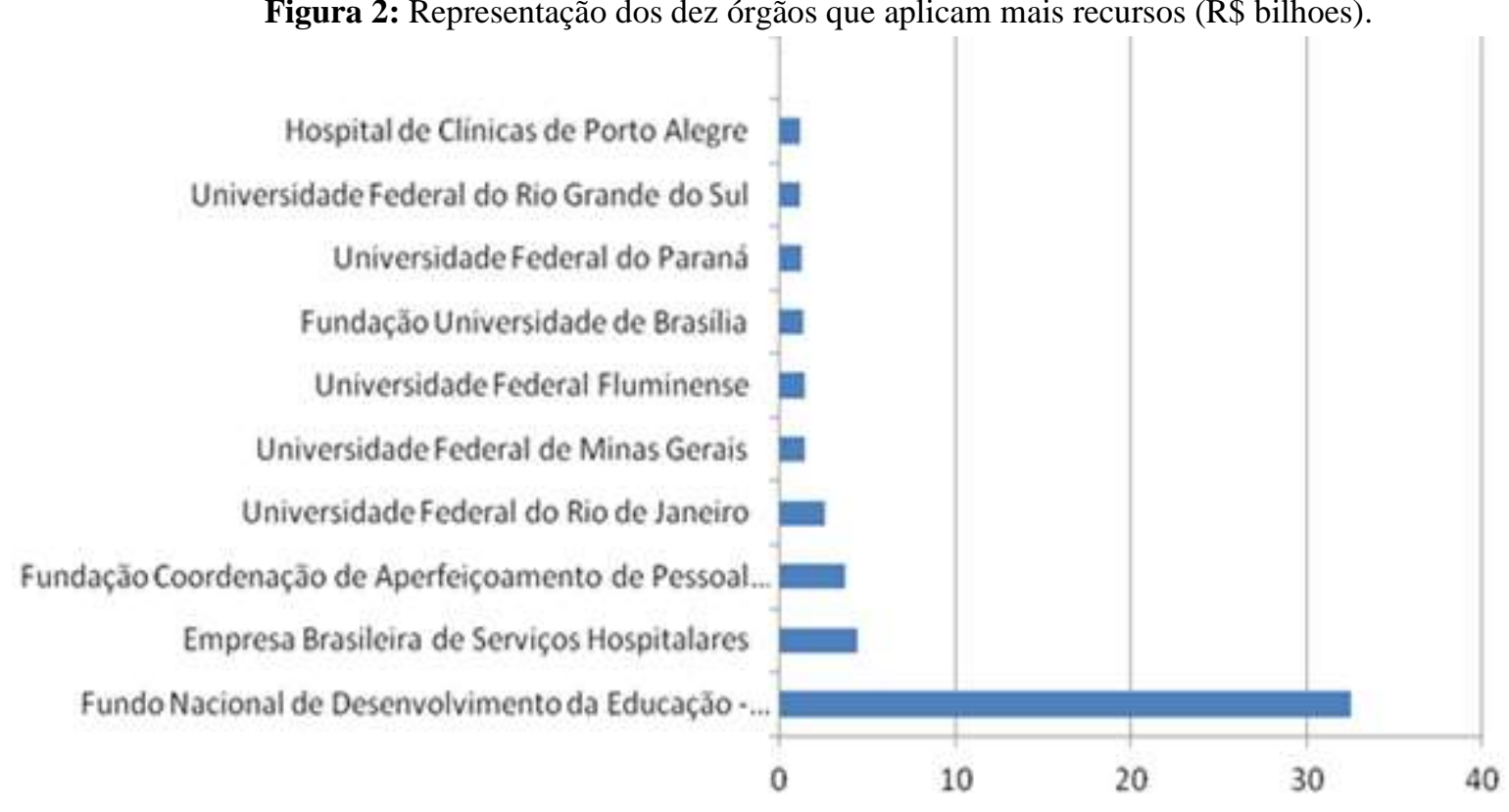

http://www.portaltransparencia.gov.br/funcoes/12-educacao?ano=2019 (2019).

Vale ressaltar que apesar da progressiva diminuição de recursos provenientes do orçamento da união para a área da educação em relação ao período de 2018 a 2020, observa-se que o FUNDEB é o órgão que mais aplica os recursos voltados para a educação, sendo responsável por 63,90\%, cerca de R \$32.502.723.860,60 no ano de 2019.

Um dos fatores preponderante, diante do quadro apresentado, é saber se os resultados correspondem ao investimento proposto, já que houve uma queda nas despesas na área da educação, principalmente se considerarmos as despesas públicas com a educação em comparação com o Produto Interno Bruto (PIB) brasileiro, que desde a criação do FUNDEB, somente nos anos de 2009, 2015 e 2016 apresentou negativo, gerando a queda em 2017 das despesas na área da educação, representado pelo gráfico da (Figura 3) a seguir.

Figura 3: Série histórica do Produto Interno Bruto (PIB) desde o ano de 1962.

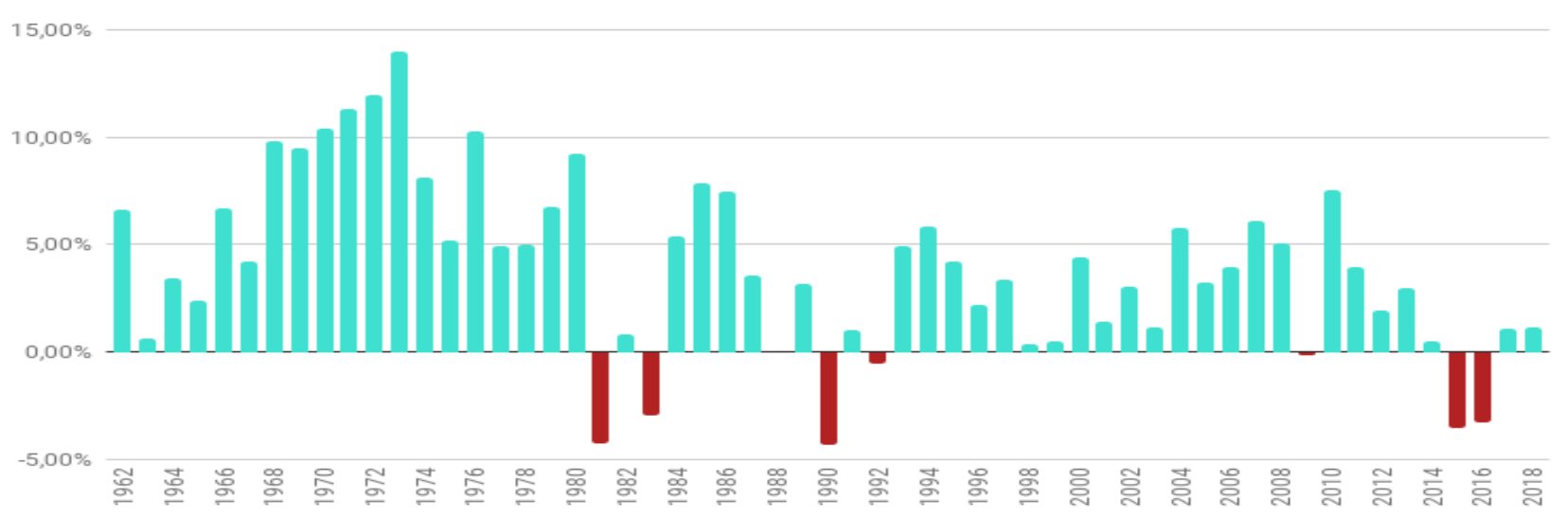

Fonte: http://www.portaltransparencia.gov.br/funcoes/12-educacao?ano=2019 (2019).

O princípio da matriz de recursos do FUNDEB tem a finalidade pela busca por desempenho, a alocação do investimento deve ser distribuído de forma a ser alcançado determinados objetivos que se traduzem em resultados, o chamado 
performance budgeting. Trata-se da forma como o orçamento é elaborado tendo como base a alocação de fundos de forma a serem obtidos resultados (OECD, 2007).

O uso sistemático de informações de desempenho para informar decisões orçamentárias, como uma entrada direta para decisões de alocação de orçamento ou como informações contextuais para informar o planejamento orçamentário e para instilar maior transparência e responsabilidade em todo o processo orçamentário, fornecendo informações aos legisladores e o público sobre os objetivos dos gastos e os resultados alcançados. (SCHICK, 2014, p. 9)

Esta ideia compreende que todo investimento feito pelo FUNDEB na educação básica são recursos que se destinam a alcançar objetivos que obtenham resultados satisfatórios no prazo estipulado pelo orçamento. Importante salientar que, o desnível socioeconômico dos pais dos alunos que frequentam a educação básica na escola pública frente ao nível socioeconômico dos alunos da escola privada, influenciam no desempenho escolar nos resultados das avaliações e variações de performance escolar. Esse é o grande dilema no resultados dos investimentos efetuados na educação básica, ou seja, a busca na qualidade do ensino.

Estabelecer uma relação comparativa entre os resultados acadêmicos obtidos pelos alunos da escola pública com os alunos da escola privada, na busca de uma maior efetividade e qualidade ao ensino, como resultado do investimento feito pelo FUNDEB, refletiria, a priori, um melhor indicador do desempenho do rendimento social no gasto do investimento por aluno ou mesmo por escola.

Do ponto de vista econômico os valores estão sendo aplicados. Mas no ponto vista de vista social, o valor aplicado pode não estar produzindo resultados satisfatórios para melhorar a qualidade de ensino na educação básica. De fato, existe um significativo impacto a ser suprido entre o valor economicamente aplicado e o resultado no desempenho escolar entre a escola pública e a escola privada na qualidade ensino, em busca de resultados acadêmicos.

Sem a compreensão e o enfrentamento das principais dificuldades para obtenção de uma melhora na qualidade do ensino no Brasil, com uma extrema desigualdade social na área educação que afeta significativamente os resultados dos alunos da educação básica da escola pública, provavelmente muitos dos gastos com a educação acentuarão sempre uma visão negativa no desempenho escolar, sendo o olhar voltado para o contexto do discurso em que os investimentos se inserem.

Para se ter uma ideia, foi divulgado em dezembro de 2019, o relatório do Programa Internacional de Avaliação de Estudantes (Pisa), a principal avaliação em educação básica, nas disciplinas de leitura, matemática e ciência, em prova mundial, onde restou constatado que 4 em 10 alunos brasileiros não aprendem o básico. Vale ressaltar que, essa avaliação é referencia mundial para a Organização para a Cooperação e Desenvolvimento Econômico (OCDE).

Nenhuma performance em resultados de qualidade é saudada pelo aumento da pobreza e da desigualdade social. Não adianta dimensionar que o investimento na área educação pode ser independente da esfera socioeconômico, por maior que seja o orçamento destinado para tais fins. A precariedade do trabalho e o crescimento do desemprego são fatores que afetam a qualidade na educação seja em que nível for.

Todo o sistema de investimento funciona em uma simbiose de dependência entre si que afeta os resultados e seus desempenhos desejados em todas as áreas. Se um lado economicamente vai mal, com certeza irá afeta o outro lado, por maior que bem administrado esteja. As orientações e práticas serão direcionadas para dar uma maior qualidade à educação dentro do espectro do todo e não tão somente em uma área específica. No domínio da educação as perspectivas giram em torno de como está funcionando todo o sistema. Daí, como demonstrado no gráfico acima em que se apresenta a tendência de queda nas despesas na área da educação, confinada às implicações econômicas em outros setores do governo.

Evidentemente que o retorno do investimento na área da educação, seja em que nível for, direciona à formação do capital humano. A sua rentabilidade é dimensionada no crescimento da cidadania, beneficiando mais a sociedade quando se refere à educação básica como é o caso do FUNDEB, pelo menos é essa a intenção. Sua concretização, para à formação do 
capital humano, mesmo com a dependência das variáveis econômicas de setores, depende de uma unicidade entre o quantitativo e o qualitativo do investimento, como forma de desempenho nos resultados apresentados, poderá trazer benefícios os quais possam mudar toda a conjuntura social e política na sociedade, valorizando o aporte financeiro a que foi confiado. Mas sem dar qualidade a educação básica, os benefícios de todo o investimento poderá ficar comprometido.

Os investimento aplicados à educação básica não podem ficar sob um dogma econômico e político. O essencial é verificar se os resultados obtidos pelo FUNDEB, como órgão que mais aplicou na educação básica, coadunam na formação do capital humano, apontando uma maior eficiência nos gastos com a educação básica, como a principal fonte de receita, justificando a continuidade do investimento nesse segmento como já vem sendo feito desde o FUNDEF.

A ascensão dos princípios econômicos do neoliberalismo que se aporta no sistema econômico globalizado, poderá trazer desvantagens em dar continuidade ao investimento de fundos de financiamento à educação básica, se somente tiver o olhar para os valores aplicados, sem levar em consideração os resultados de desempenho que mereçam ser reforçados em um novo investimento. Se o guia for os valores investidos pode dar a impressão de que os resultados foram satisfatórios na formação do capital humano.

No Brasil, a diferença de desempenho entre aqueles com nível socioeconômico alto e aqueles com nível baixo, foi de 97 pontos em leitura, o que equivale a quase três anos de estudo. Essa diferença superou a média da OCDE, que é de 89 pontos. (Revista Isto é, 2019)

Os estudantes brasileiros com condição socioeconômica e cultural mais elevada são piores em leitura em comparação aos alunos pobres de outros países, como a China. Na disciplina Leitura, o Brasil ficou na $57^{\mathrm{a}}$ colocação no ranking da OCDE (Organização para Cooperação e Desenvolvimento Econômico), com nota 413 - a média geral foi 487. (Revista Veja, 2019)

Os dados divulgados pelo Pisa só reforça a falta de qualitativo nos investimentos do FUNDEB ao longo dos anos de sua vigência. Uma política educacional de qualidade não se processa de forma linear. Se deve levar em consideração diversas variáveis nos complexos de fatores sociais, principalmente na atuação dos Estados, para se buscar um melhor desempenho dos alunos brasileiros nas avaliações do Pisa que irá se realizar em 2020.

As escolas brasileiras devem direcionar ações qualitativas de aprendizagem, mesmo considerando um possível ambiente socioeconômico desfavorável. Valorizar a aprendizagem dos alunos com métodos eficazes para dar uma maior qualidade ao ensino, estabelecendo uma meta de uma política educacional forte no plano nacional, com atuação do Estado, em conjunto com as forças econômicas, políticas e sociais para diminuir o desnível socioeconômico entre os alunos das escolas públicas e particulares, como assim o fazem países que se encontram muito acima do Brasil no Pisa.

A desigualdade social tem um significativo impacto sobre o desempenho dos alunos da educação básica nos resultados apresentado pelo Pisa. Essa desigualdade afeta significativamente os alunos brasileiros e é uma das causas, dentro outros fatores, como a falta de qualificação do investimento na educação, a falta de metodologias e métodos inovadores no processo de ensino e aprendizagem que apresenta esse baixo rendimento. É necessário entender que esse aspecto social termina por desvirtuar todo um processo de tentativa de melhoramento na educação.

A violência doméstica é um fator que traz um desequilíbrio psicológico e que tem afetado muito o rendimentos dos alunos brasileiros não só nos sistemas de avaliações externas mas as internas também. Os alunos não podem aprender com o medo de sofrerem sanções físicas e psicológicas em face de seus fracos rendimentos escolares. Chegou o momento de resgatar os alunos e não deixa-los reféns de sanções físicas e psicológicas causado pelo fraco rendimento escolar, mitas vezes ocasionados por fatores os quais eles nunca contribuíram. O medo paralisa e muitas vezes reduz a cognição na aprendizagem.

Os recursos na forma que estão sendo aplicados nem sempre servem à política educacional baseado no desempenho performance-based funding. É necessário agregar o investimento a um direcionamento mais eficaz e eficiente à educação 
básica, equilibrando as necessidades entre os desníveis sociais dos alunos, com objetivos direcionados a um melhor desempenho nas avaliações globais e locais.

Para isso, é necessário que se façam reformas políticas que visem recompor os desníveis sociais, as desigualdades, uma melhor qualidade de vida, agregando valores à formação do capital humano desde a educação básica. Deixar de fora as discussões de contra-ciclos ideológicos ligados direta ou indiretamente a interesses de discursos políticos e focar em conjunto de iniciativas na área da educação básica com fluxo de investimento que possam melhorar a qualidade no processo de ensino e aprendizagem, mensurado por recurso a exames periódicos que possam identificar falhas no sistema de avaliação para que se possa reforçar com técnicas didáticas melhorias na educação, é uma remodelagem profunda nos instrumentos que possam agregar novos direcionamentos à educação brasileira.

Todo esse processo depende de discussões as quais se possam responder as indagações de como os nossos alunos estão sendo ensinados; quais as circunstâncias de como se está sendo ensinado; quem está ensinando e o que é ensinado.

\section{Considerações Finais}

Apesar de se tratar de uma analise sociológica mais complexa, precisa-se urgente redefinir parte do investimento na construção de estruturas físicas de novos ambientes escolares onde alunos e professores possam se servir de tecnologias no processo de ensino e aprendizagem. Valorizar parcerias entre os setores público e privado integralizando os atores (alunos e professores) na troca de informações para consecuções de objetivos comuns na área da educação e dar uma maior autonomia aos profissionais na área da educação, com formação contínua estimulado a partir de novas metodologias, de novos projetos com disrupturas no ensino tradicional, com significativo reforço do papel emancipador de potência criativa, são algumas das condições que experimentadas, planejadas e estudadas, possam dar um maior impulso na busca de melhores resultados não só avaliativos mas pessoal de nossos alunos.

O que se deve esquecer são os processos determinados por ciclos que de forma repetitiva não alcança resultados satisfativos internos e externos na educação básica, retomando sempre as problemáticas do passado ao mesmo lugar de onde sequer consegue sair, criando uma sensação de impotência, desmotivação, futilidade e desinteresse no processo de qualquer progresso no ensino.

Ter a percepção de que não tão somente o incentivo é meramente material mudaria muito o desempenho dos alunos da educação básica brasileira. Não se pode dar continuidade a uma boa prática educativa com o pensamento voltado para fórmulas passada no ensino. Os tempos são outros. O sentindo materialista de se atingir objetivos externos, muitos deles impostos de formas mecânicas, não tem dado os resultados esperados. Há de fato uma mudança que precisa ser entendida em matéria de educação. A disruptura se faz presente no contexto atual.

Os desafios a serem enfrentados são globais e não tão somente internos. A modernização do papel da escola, os avanços das reformas políticas que visem diminuir consideravelmente o plano das desigualdades sociais, são contextos racionais de decisões dentro de uma perspectiva que devem ser enfrentado no processos de mudança que a atualidade exige, sem recuo histórico no atraso de uma construção de uma escola de qualidade na educação básica, seguindo estudos de modelos de outro países que avançam sobre essa perspectiva.

Além disso, deve-se estimular o desenvolvimento da criatividade no sistema de educação, favorecendo o desenvolvimento e potencialidade dos alunos, com professores motivados, utilizando práticas pedagógicas criativas, com novas abordagens de transmissão de conhecimento, tirando em parte todo o peso do determinismo de técnica mecânicas objetivas no aprendizado direcionado tão somente à resolução de problemas, o que se demonstra, pelos resultados apresentados, que essa técnica não tem surtido nenhum efeito. 
A busca por uma identidade educacional que vise melhorar os resultados de avaliações internas e externas dos alunos da educação básica no Brasil, para obterem desempenho satisfatórios justificando os investimentos nessa área, evitando, com isso que se venha a desconstruir todo um processo de formação de capital humano, e seguir uma tendência de uma agenda global em politicas educacionais, sem que essa sobreponha a qualquer uma praticada no país, é descontinuar todo o processo de ensino e aprendizagem que está sendo aplicado, revisando novos valores para a educação, com implicações subjetivas e objetivas na didática e não tão somente o ensino mecânico, além de aplicações políticas no âmbito externo da escola que influenciam diretamente na educação.

Esses fatores internos e externos são primordiais para que em um futuro bem próximo possamos melhorar a qualidade de nosso alunos e com isso melhorar os seus desempenhos em todas as avaliações que forem elaboradas. Sem um planejamento de qualidade nada se irá conquistar e cada vez mais estaremos desestimulando a nossa maior riqueza que é a formação de uma geração de notáveis. Reverter esse processo demanda uma linha de movimento descontínuo ao que se apresenta.

Nas palavras de Adorno (1995, p. 170) o talento não se encontra previamente configurado nos homens, mas que, em seu desenvolvimento, ele depende do desafio a que cada um é submetido. Isto quer dizer que é possível "conferir talento" a alguém. A partir disto a possibilidade de levar cada um a "aprender por intermédio da motivação" converte-se numa forma particular do desenvolvimento da emancipação.

\section{Agradecimentos}

Agradeço ao apoio da Universidade Federal do Ceará - UFC, da Universidade da Integração Internacional da Lusofonia-Unilab, e demais pesquisadores pelo desenvolvimento a essa pesquisa.

\section{Referências}

Adorno, T. W. Educação e emancipação.Trad. Wolfgang Leo Maar. Paz e Terra (1995).

Alunos ricos no brasil são piores em leitura que pobres de outros países. Revista Veja, https://veja.abril.com.br/educacao/alunos-ricos-no-brasil-sao-piores-emleitura-que-pobres-de-outros-paises/.

Araújo \& Oliveira, J. B. Financiamento da educação: breve histórico. In.: Araújo \& Oliveira, Batista, J. et al. Financiamento da Educação Básica no Brasil. Brasília: Comissão de Educação e Cultura Câmara dos Deputados, 2019.

Brasil, Lei de Diretrizes e Bases (LDB). (1996).Lei 9.394 de 20 de dezembro de 1996. Brasília.

Brasil, Lei Complementar $n^{\circ} 101$, de 04 de maior de 2000. Estabelece normas de finanças públicas voltadas para a responsabilidade na gestão fiscal e dá outras providências. (Lei de Responsabilidade Fiscal - LRF). http://www.planalto.gov.br/CCIVIL/Leis/ LCP/Lcp101.

Brasil, Constituição Federal de 1988. Constituição da República Federativa do Brasil de 1988. http://www.planalto.gov.br/ccivil_03/Constituicao/Constitui\%C3\%A 7ao.

Brasil, Tribunal de Contas da União. Auditoria coordenada educação. Instituto Rui Barbosa; Tribunal de Contas da União. Brasília: TCU, 2014.

Curristine, T. Government Performance: Lessons and Challenges. OECD Journal on Budgeting, 5(1), 127-151.https://www.oecd-ilibrary.org/governmentperformance_519n6d35xsf0.pdf?itemId=\%2Fcontent $\% 2$ Fpaper\%2Fbudget-v5-art6-en\&mimeType=pdf.

INEP. Cadernos de estudos e pesquisas em políticas educacionais. Bof, A.M \& Oliveira, A.S de (organizadores). Brasília: Instituto Nacional de Estudos e Pesquisas Educacionais Anísio Teixeira.

Martins, P. S. O financiamento da educação básica como política pública. Revista Brasileira de Política e Administração da educação, 26(3), 497-514.

Marx, K. Contribuição à crítica da economia política. Trad. e intro. Florestan, F. Editora Expressão Popular.

Menezes, N. Financiamento e gestão: desafios para a educação Brasil. In.: Araújo \& Oliveira, Batista, J. et al. Financiamento da Educação Básica no Brasil. Brasília: Comissão de Educação e Cultura Câmara dos Deputados, 2019.

OECD. (2007). Performance Budgeting in OECD Countries. OECD Publishing. http://www.planejamento.gov.br\%2Fsecretarias\%2Fupload\%2 FArquivos\%2Fseges\%2Farquivos\%2Focde2011\%2Foecd_performance_countries.pdf\&usg=AOvVaw0M6uW2YXqr-QNYesGGn8We. 
Research, Society and Development, v. 10, n. 2, e46510212468, 2021

(CC BY 4.0) | ISSN 2525-3409 | DOI: http://dx.doi.org/10.33448/rsd-v10i2.12468

OECD. (2019) Best practices for performance budgeting. https://one.oecd.org > GOV > PGC > SBO(2018)7 >.

Pinto, J. M. de R. O financiamento da educação na Constituição Federal de 1988: 30 anos de mobilização social. Educação \& Sociedade, Campinas, v. 39, n. 145 , p. 846-869, 2018.

PISA: Brasil tem leve melhora em prova mundial, mas 4 em 10 alunos não aprendem o básico. Revista Isto É. https://istoe.com.br/2-dos-alunos-brasileirostem-nota-maxima-em-avaliacao-internacional/.

Politi, R. B. In.: Araújo; Oliveira \& Batista, J. et al. Financiamento da Educação Básica no Brasil. Brasília: Comissão de Educação e Cultura Câmara dos Deputados, 2019.

Schick, A. The metamorphoses of performance budgeting. OECD Journal on Budgeting, 13/2, https://doi.org/10.1787/budget-13-5jz2jw9szgs8. (2014).

Silva, T. Financiamento e Qualidade da Educação Pública. In.: Araújo; Oliveira, Batista, J. et al. Financiamento da Educação Básica no Brasil. Brasília: Comissão de Educação e Cultura Câmara dos Deputados, 2019.

Strehl, F.; Reisinger, S. \& Kalatschan, M. (2006). Funding Systems and Their Effects on Higher Education Systems. Higher Education, (6). http://www.oecdilibrary.org/docserver/download/514rvsv3czmr.pdf?expires=1424730776\&id=id\&accname=guest\&check sum=4FB5333A2BA0321BBDAD3A0A1F0F9F7C 